6 Oldbring J, Mikulowski P. Malignant melanoma of the penis and male urethra: report of nine cases and review of the literature Cancer 1987;59:581-7.

7 Pow Sang JM, Klimbert IW, Hackett RL, Wajsman Z. Primary malignant melanoma of the male urethra. $\mathcal{f}$ Uro 1988;139:1304-6.
$8 \mathrm{Katz}$ JI, Grabstald H. Primary malignant melanoma of the female urethra. 7 Urol 1976;116:454-7.

9 Manivel JC, Fraley EE. Malignant melanoma of the penis and male urethra: 4 case reports and literature review. $\mathcal{F}$ Urol 1988;139:817-8.

\title{
Mucopolysaccharidosis type VII associated with hydrops fetalis: histopathological and ultrastructural features with genetic implications
}

\author{
A J Molyneux, E Blair, N Coleman, P Daish
}

Department of

Cellular Pathology,

Northampton General

Hospital NHS Trust,

Northampton

A J Molyneux

Department of Clinical Genetics, Churchill Hospital, Oxford

E Blair

Department of

Histopathology,

Addenbrooke's

Hospital, Hills Road,

Cambridge

N Coleman

Department of

Paediatrics,

Northampton General

Hospital NHS Trust,

Billing Road,

Northampton

NN1 5BD

$P$ Daish

Correspondence to:

Dr A J Molyneux.

Accepted for publication 10 December 1996

\begin{abstract}
A case of mucopolysaccharidosis type VII (MPS VII, B glucuronidase deficiency) causing fatal hydrops fetalis in the third trimester is presented. The diagnosis was suspected on histopathological examination by the presence of foam cells in many of the viscera and foamy change in the placental Hofbauer cells. Electron microscopy showed empty cytoplasmic inclusion bodies within macrophages and in the Hofbauer cells. Enzyme assay of cultured fibroblasts showed markedly deficient $\beta$ glucuronidase activity, thus confirming the diagnosis. A detailed and thorough histopathological examination of hydrops fetalis cases is important to detect subtle features of inherited metabolic disorders. Use of a structured necropsy protocol is recommended for cases of non-immune hydrops. Electron microscopy is a useful adjunct to light microscopy in cases where an inherited metabolic disorder is suspected. Precise necropsy diagnosis is important as there are implications for genetic counselling and possible prenatal diagnosis in subsequent pregnancies.

(f Clin Pathol 1997;50:252-254)
\end{abstract}

Keywords: mucopolysaccharidosis type VII; hydrops fetalis; electron microscopy.

\section{Case report}

This boy was the second child of healthy unrelated parents. Their first child, a girl aged three years, is well. The boy was delivered by caesarean section for fetal distress at 32 weeks' gestation. Birth weight was $3.06 \mathrm{~kg}$ (3.6 standard deviations above the mean). Gross hydrops was noted and there was no detectable heart beat. Attempts at resuscitation were unsuccessful. Initial investigations including direct Coombs test, haemoglobin electrophoresis, and parvovirus B19 IgM tires revealed no obvious cause for the hydrops.
PATHOLOGICAL FINDINGS

External examination confirmed a grossly hydropic male baby. Assessment of the facies was complicated by oedema but it was not obviously abnormal. Internal examination revealed a dilated heart and pulmonary hypoplasia (combined weight $10.6 \mathrm{~g}$, expected $34 \pm 11$ g; lung/body weight ratio 0.003 ). The liver was pale and slightly enlarged (82.4 g, expected $65 \pm 22 \mathrm{~g}$ ) and there was splenomegaly (19.6 g, expected $4.1 \pm 2.1 \mathrm{~g}$ ). There were blood stained pleural and peritoneal effusions and there was fresh haemorrhage into soft tissues in the neck and mesentery. Other gross features were unremarkable and there were no malformations.

The placenta was large (fixed weight $765 \mathrm{~g}$ ) but otherwise appeared grossly normal.

Microscopic examination showed finely vacuolated interstitial foamy cells present in many organs, but most noticeably in the spleen, lung, myocardium, bowel mucosa, and bone marrow (fig 1). Similar vacuolation was seen in hepatocytes, proximal convoluted tubules, and cerebral cortex, probably in microglial cells. The placenta also showed a subtle vacuolation of villous Hofbauer cells and a normal appearance of the cytotrophoblast, features suggestive of MPS VII. Electron microscopy of lung tissue showed numerous mainly empty cytoplasmic vacuoles (fig 2). Although not specific, the ultrastructural findings also suggested the possibility of a metabolic storage disorder.

The diagnosis of MPS VII was confirmed by quantitation of enzyme activity in cultured fibroblasts. $\beta$ Glucuronidase enzyme activity was negligible $(0.27 \mathrm{nmol} / \mathrm{h} / \mathrm{mg}$ protein, normal range $48-360 \mathrm{nmol} / \mathrm{h} / \mathrm{mg}$ protein). Control enzymes ( $\beta$ galactosidase and $\alpha$ fucosidase) showed activity within their normal ranges.

\section{Discussion}

A wide variety of conditions may give rise to non-immune hydrops fetalis, and a structured approach to the perinatal necropsy is therefore 


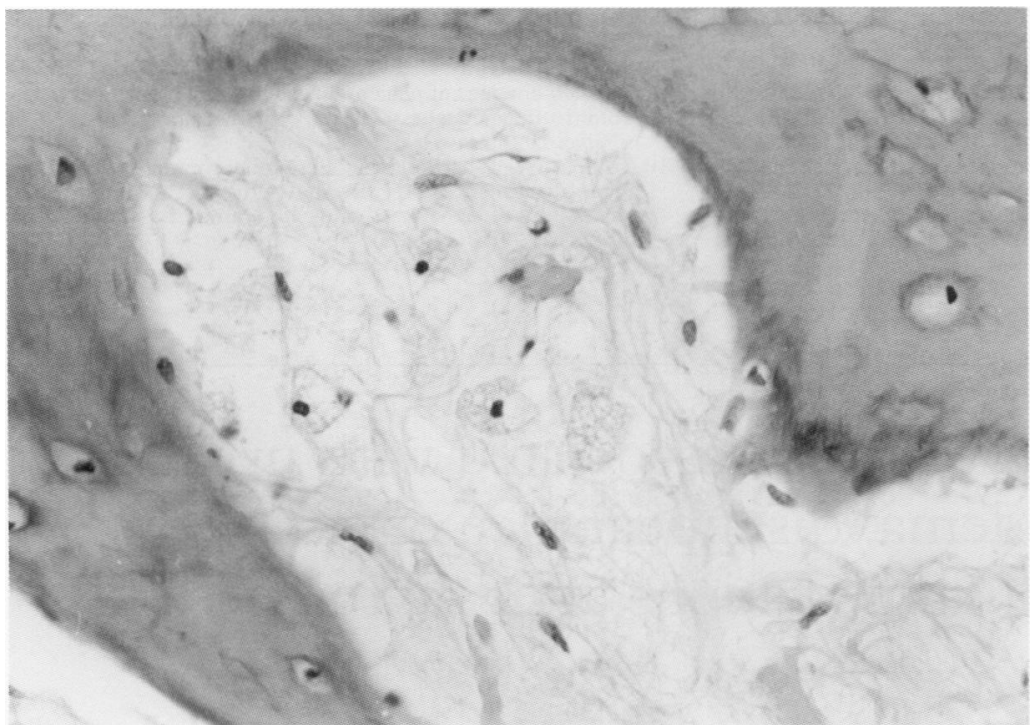

Figure 1 A section of rib with scattered macrophages within the bone marrow spaces showing fine cytoplasmic vacuolation (haematoxylin and eosin, high power).

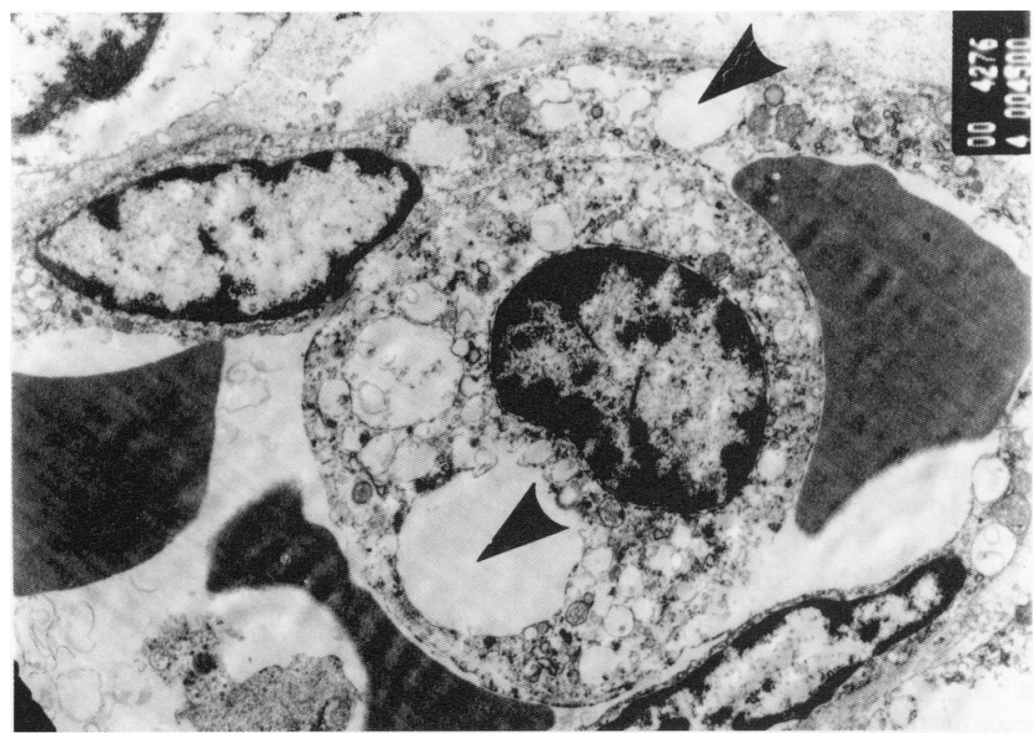

Figure 2 Ultrastructural appearance of pulmonary capillary. Vacuoles are prominent in the leucocyte and in the endothelial cells (arrowheads). Most vacuoles appeared empty, although some contained floccular material and others a few lamellae (× 3390).

especially important. Perinatal necropsy protocols for non-immune hydrops cases emphasise the importance of a complete examination including whole body $x$ ray, thorough gross dissection, placental examination, microscopic examination, microbiological cultures, and tissue (fibroblast) culture. ${ }^{1}$ The latter may be unsuccessful, particularly in cases of stillbirth with postmortem retention in excess of 24 hours. Although placental amnion is a good backup tissue for culture, we also advocate inclusion of sample collection for electron microscopy in the protocol for cases where the initial gross examination fails to show a cause for the hydrops. Electron microscopy may significantly reduce the differential diagnosis where an inherited metabolic disorder is suspected on light microscopy. In some cases (for example, $\mathrm{GM}_{1}$ gangliosidosis and Gaucher's disease) the inclusions seen on electron microscopy may be diagnostic even in the macerated fetus. $^{2}$

Mucopolysaccharidosis type VII is a rare autosomal recessive condition which results from a deficient function of the enzyme $\beta$ glucuronidase. ${ }^{3}$ This glycoprotein is required for the hydrolysis of glucuronic acid residues from the non-reducing termini of glycosamuroglycans of lysosomes. Deficiency of glucuronidase results in the accumulation of glycosaminoglycans in many organs and increased urinary excretion of glycosaminoglycans.

The $\beta$ glucuronidase gene has been mapped to $7 \mathrm{q}$ and has been isolated and characterised by molecular genetic studies. ${ }^{4}$ Twelve separate disease causing mutations have been identified and this molecular heterogeneity may in part explain the variable onset from the perinatal period to early childhood. ${ }^{5}$ Those affected may present with hydrops fetalis or later with Hurler features. ${ }^{6-8}$

The pathological features of MPS VII have not been studied extensively. The degree and distribution of cellular vacuolation within organs appears to be variable, but the liver and spleen have been reported as showing the changes consistently. ${ }^{1}$ Vacuolation of chorionic villous Hofbauer cells in the presence of a normal cytotrophoblast layer is a microscopic feature which should alert the pathologist dealing with a case of hydrops to a probable diagnosis of an inherited metabolic disorder. In this context, this pattern of vacuolation within the chorionic villus is characteristic of MPS VII, but other metabolic disorders (notably $\mathrm{GM}_{1}$ gangliosidosis, sialidosis, and mucolipidosis II) may show vacuolation of the cytotrophoblast with less conspicuous villous Hofbauer cells. ${ }^{29}$

A diagnosis of MPS VII following necropsy examination has important implications for future pregnancies. Prenatal diagnosis is now possible following chorionic villus sampling or amniocentesis by $\beta$ glucuronidase assay or direct gene analysis. ${ }^{10}$

In our case the diagnosis of MPS VII was suspected on the basis of the histopathological examination. The ultrastructural appearances aided the diagnosis by excluding many other types of inherited metabolic disorder with characteristic inclusion bodies, for example $\mathrm{GM}_{1}$ gangliosidosis. The electron microscopic appearances reflected the empty appearance of cytoplasmic vacuoles on light microscopy and the failure to stain with the periodic-acid-Schiff reaction.

We thank Dr A H Fensom and C P Ward of the Supraregional Laboratory for Genetic Enzyme Defects, SE Thames Regional Genetics Centre, Guy's Hospital, London, for carrying out the enzyme tests. Thanks also to $\mathrm{Dr} S \mathrm{M}$ Huson, Department of Medical Genetics, Churchill Hospital, Oxford, for her helpfu comments.

1 Keeling JW. Hydrops fetalis and other forms of excess fluid accumulation in the fetus. In: Wigglesworth JS, Singer DB, eds. Textbook of fetal and perinatal pathology. Boston: Blackwell Scientific Publications, 1991:429-54.

2 Dimmick JE, Applegarth DA. Inborn metabolic diseases of the perinatal infant. In: Wigglesworth JS, Singer DB, eds The perinatal infant. In: Wiggleswh pathology Boston: Blackwell Textbook of fetal and perinatal pathology.

3 Neufeld EF, Muenzer J. In: Scriver C, Beauclef AL Sly WS Valle D, eds. The metabolic and molecular basis of inherited Valle D, eds. The metabolic and molecular basis of

4 Miller RD, Hoffmann JW, Powell PP, Kyle JW, Shipley JM, Backinsky DR, et al. Cloning and characterisation of the hackinsky DR, et al. Cloning and characterisation of the human beta-glucuronidase gene. Genomics 1990;7:208-83.
Yamada S, Tomatsu S, Sly WS, Islam R, Wenger DA, Yamada S, Tomatsu S, Sly WS, Islam R, Wenger DA
Fukuda S, et al. Four novel mutations in mucopolysaccharidosis type VII including a unique base substitution in 
exon 10 of the beta-glucuronidase gene that creates a novel $5^{1}$ splice site. Hum Mol Genet 1994;4:651-5. Kagie MJ, Kleijer WJ, Huijmans JG, Maaswinkel-Mooy P, Kanhai HH. Beta-glucuronidase deficiency as a cause of fetal hydrops. Am f Med Genet 1992;42:693-5.

7 Nelson A, Pederson L, Frampton B, Sly WS. Mucopolysaccharidosis VII (beta glucuronidase deficiency) presentin as non-immune hydrops fetalis. $\mathcal{F}$ Pediatr 1982;101:574-6.

8 Irani D, Kin HS, El-Hibri H, Dutton RV, Beaudet A, Armstrong D. Postmortem observations on beta glucuronidase deficiency presenting as hydrops fetalis. Ann Neurol 1983;14:486-90.

9 Nelson J, Kenny B, O'Hara D, Harper A, Broadhead D. Foamy changes of placental cells in probable beta glucuronidase deficiency associated with hydrops fetalis. $\mathcal{f}$ Clin Pathol 1993;46:370-1.

10 Chabas A, Guardiola A. Beta-glucuronidase deficiency: identification of an affected fetus with simultaneous sampling of chorionic villus and amniotic fluid. Prenat Diagn 1993;13:429-33.

\title{
Hashimoto's thyroiditis associated with urticaria and angio-oedema: disappearance of cutaneous and mucosal manifestations after thyroidectomy
}

\author{
Antonio Amoroso, Pierluigi Garzia, Cynthia Pasquarelli, Giuseppe Sportelli, \\ Antonella Afeltra
}

University of Rome

"La Sapienza", Rome, Italy:

Department of Clinical

Medicine

A Amoroso

P Garzia

C Pasquarelli

A Afeltra

Institute of Clinical

Surgery II

Giuseppe Sportelli

Correspondence to: Antonella Afeltra MD, Dept Medicina Clinica, Viale dell'Università, 37 - 00185 Rome, Italy.

Accepted for publication 10 December 1996

\begin{abstract}
A 60 year old woman affected by Hashimoto's thyroiditis presented with a history of recurring episodes of urticaria and angio-oedema. Clinical and laboratory evaluation of the patient excluded allergy to external agents, hereditary angiooedema, and occult infections. $A$ pathogenic relation between Hashimoto's thyroiditis and chronic urticaria/angiooedema was suspected. However, treatment with L-thyroxine had no influence on the frequency and severity of the cutaneous and mucosal manifestations, which occurred almost daily and required repeated administration of steroids. The patient therefore underwent total thyroidectomy. Cytometric analysis of intrathyroidal lymphocyte subsets showed unusual abnormalities. Urticaria and angio-oedema completely remitted after surgery; 18 months postoperatively the patient was still asymptomatic.

(f Clin Pathol 1997;50:254-256)
\end{abstract}

Keywords: Hashimoto's thyroiditis; urticaria-angiooedema; intrathyroidal lymphocyte subsets.

Hashimoto's thyroiditis is an organ specific autoimmune disease characterised by an intense thyroid infiltrate of mononuclear cells. It predominantly affects women. Clinical presentation is thyroid enlargement associated with hypothyroidism. Antithyroid antibodies are found in most cases.

Urticaria is a well demarcated skin reaction characterised by oedema involving the superficial portion of the dermis. Lesions are raised and erythematous, and usually pruritic. Angiooedema differs from urticaria in that the oedematous process is located in the deep dermis and subcutaneous or submucosal tissues. Furthermore, lesions are more painful than pruritic. The involvement of the upper respira- tory tract may result in severe and sometimes fatal complications.

Recently an association between idiopathic chronic urticaria and autoimmune thyroiditis has been reported, but its pathogenic mechanisms are still unknown. ${ }^{1-7}$ In this paper we describe the case of a 60 year old woman affected by Hashimoto's thyroiditis associated with cutaneous and mucosal manifestations of urticaria and angio-oedema. The patient underwent total thyroidectomy, and a cytometric analysis of intrathyroidal and peripheral blood lymphocyte subsets was performed. Surgery was followed by a complete remission of urticaria and angio-oedema; 18 months postoperatively the patient was still asymptomatic.

\section{Case report}

A 60 year old woman was admitted to our department in January 1995. Her family history was unremarkable. She had been healthy until July 1993 when thyroid enlargement appeared and raised serum titres of thyroid microsomal and thyroglobulin antibodies were documented; at the same time thyroid function tests showed $\mathrm{FT}_{3}$ and $\mathrm{FT}_{4}$ values within the normal range and high $\mathrm{TSH}$ levels. Because of these results, L-thyroxine treatment $(0.1 \mathrm{mg} /$ day) was started.

In March 1994 the patient presented with episodes characterised by urticarial lesions involving the face and trunk, accompanied by swelling of the lips and tongue. Allergy tests were performed, but total IgE (PRIST) and C1-INH values were within the normal range. Routine laboratory analysis revealed only an increase of erythrocyte sedimentation rate (ESR) of $40 \mathrm{~mm} / \mathrm{h}$. During the following months attacks of urticaria and angio-oedema recurred, with progressively increasing frequency and severity; on several occasions, airway involvement caused respiratory obstruction. Attacks were treated with steroids (betamethasone, $4 \mathrm{mg}$ intravenously). Continuous 